\title{
Measuring Mobile Banking Adoption in Uganda Using the Technology Acceptance Model (TAM2) and Perceived Risk
}

\author{
Nalugoti Milly, Shoukui Xun, Megan Emfosi Meena, Benjamin Blandful Cobbinah \\ Anhui University of Science and Technology, Huainan, China \\ Email: Millykay7@gmail.com,xunshoukui@qq.com, megan.meena17@gmail.com, bencobbah421@gmail.com
}

How to cite this paper: Milly, N., Xun, S. K., Meena, M. E., \& Cobbinah, B. B. (2021). Measuring Mobile Banking Adoption in Uganda Using the Technology Acceptance Model (TAM2) and Perceived Risk. Open Journal of Business and Management, 9, 397-418.

https://doi.org/10.4236/ojbm.2021.91021

Received: November 5, 2020

Accepted: January 26, 2021

Published: January 29, 2021

Copyright ( 2021 by author(s) and Scientific Research Publishing Inc. This work is licensed under the Creative Commons Attribution International License (CC BY 4.0).

http://creativecommons.org/licenses/by/4.0/ (c) (i) Open Access

\begin{abstract}
The purpose of this study is to measure the adoption of mobile banking systems among the citizens of Uganda by analyzing the effect of perceived usefulness, perceived ease of use, and perceived risk on actual usage of mobile banking, with intention to use as a mediating variable. A closed-ended questionnaire was employed to be filled by Uganda citizens. A total of 275 questionnaires were sent out, among which only 245 were useable. A factor analysis test was run in order to establish the construct validity of the questionnaire. After that, Cronbach's alpha was used to measure the reliability of the study, and multiple linear regression analysis, Pearson's correlation, ANOVA table, and process analysis was used to analyze the association between the variables. The findings of our study showed a good and acceptable model fit. Perceived usefulness and perceived ease of use were significantly correlated to actual usage, with intention to use as a positive mediator. Perceived risk had a negative relationship with actual usage of mobile banking where intention to use negatively mediates the relationship. This study can be used by the banking industry of Uganda as well as clients of banks. It poses in detail the advantages and the risks of using mobile banking system. The banking industry can use it to maximize on the advantages while minimizing the risks, and the clients can make use of this study to further gain knowledge about the benefits and risks and make an informed decision on whether to use the mobile banking system or not. The respondents' pool of this study was constricted, employing only the citizens of Uganda. Moreover, this research was conducted on a cross-sectional basis with quantitative and closed-ended questionnaire. Future researchers can employ a diverse pool of respondents to get variable responses. Moreover, the study can be conducted on a longitudinal basis, while also employing the use of open-ended questionnaire to get a better insight regarding mobile banking systems.
\end{abstract}




\section{Keywords}

Mobile Banking Adoption, Technology Acceptance Model, TAM2, Uganda, Mobile Banking System, Perceived Risk, Perceived Usefulness, Perceived Ease of Use, Intention to Use, Actual Usage

\section{Introduction}

The days when people had to rely on electricity engaged personal computers to get access to the internet and their financial information are long gone. In today's era, everything is made easier through the use of mobile phones whose reach is far and wide. People rely on their hand-held devices for almost everything and claim that their phone has all the essentials that they need.

Due to the rapid technological changes in the past decade, many banks, have switched their traditional brick-and-mortar workplaces into online workplaces for themselves as well as their clients. This facilitates them in a number of ways such as declined costs, sustainable competitive advantage, convenience for employees as well as clients, and reaching a wide range of customers (Peevers, Douglas and Jack, 2008; Porteous, 2006; Koenig-Lewis, Palmer, \& Moll, 2010).

Mobile banking is described as a platform through which customers can get in touch with their banks by the use of a mobile device i.e. a smartphone, a touch phone or a Personal Digital Assistant (PDA) (Barnes and Corbitt, 2003). Other researchers have also identified different advantages of mobile banking such as accessibility, flexibility, ubiquity, interactivity and coverage (Sulaiman, Jaafar and Mohezar, 2007; Turban et al., 2006).

Uganda is characterized as the least developed country of all the developing countries. In the developing countries, a lot of its residents have mobiles but do not have bank accounts (Nassiwa, 2019). Therefore, having the banks shift to mobile banking will make it easier for the residents of Uganda to enable and manage their bank accounts that will further facilitate them in various ways such as checking the bank balance at home, savings, transfer of funds, payment of their bills, and downloading the receipts and deposit slips with ease and through the comfort of their home. In order to do this, the banks, as well as, the clients must find the value in mobile banking and be comfortable in using it. This includes a cost-benefit of analysis of the risks posed by the technology and the usefulness of the technology. This reason led us to use the Technology Acceptance Model 2 (TAM2) posited by Venkatesh and Davis (2000).

Hence, this research aims to examine the trend of adoption of mobile banking in Uganda through the use of Technology Acceptance Model 2 (TAM2) with an additional variable of perceived risk. Specifically, this study will aim at discovering the correlation among perceived usefulness, perceived ease of use, and perceived risk with intention to use and finally actually using the mobile banking technology. This paper will follow a structural flow of literature review, after 
with research methodology will be discussed, which will take us to results and discussion and finally conclusion and confines of the study.

\section{Literature Review}

In this section we introduce our variables and provide literature on them from previous researches that have been conducted with these variables. Our model includes the Technology Acceptance Model (TAM2) with an additional variable of perceived risk to analyze the adoption of mobile banking in Uganda. We have added perceived risk with the TAM2 model because we believe it will strengthen the relationship and provide a more meaningful and deeper insight into the respondents' intention and actual use of the mobile banking system.

\subsection{Technology Acceptance Model}

Fishbein and Ajzen (1975) posited a Theory of Reasoned Action (TRA) that has been used and tested by multiple scholars and serves as a basis for understanding the behavior of humans in different domains (Chen et al., 2002). Inspired by this theory, another theory was posited by Davis (1989) which came to be known as Technology Acceptance Model (TAM), which has been experimented with and later extended (Davis, 1989; Igbaria et al., 1997; Venkatesh and Morris, 2000). The original theory articulated by Davis (1989) consisted of five variables in a model which include perceived usefulness (PU), perceived ease of use (PEOU), attitude, behavioral intention to use (ITU) and actual usage (AU). The two vital determinants to predict the usage of any system are PU and PEOU.

After countless researches related to this model, some researchers stated that there was a need for supplementary variables that must be attached with the original TAM model to strengthen it (Legris, Ingham and Collerette, 2003). In response to this, another extended version of this theory was introduced by Venkatesh and Davis (2000) which further consisted of social influence processes (subjective norm, voluntarism, image), and cognitive instrumental processes (job relevance, result demonstrability), and which left out attitude towards using. Taylor and Todd's (1995) research was consistent with this finding as they stated that social influence and cognitive instrumental processes had an effect on actual usage and PU and PEOU also affected usage behavior through ITU.

\subsubsection{Perceived Usefulness (PU)}

Perceived usefulness is described by Davis (1989) and Mathwick, Malhotra and Rigdon (2001) as the degree to which a person trusts that making use of a certain technological and innovative system would enhance his productivity and output. Lopez-Nicolas, Molina-Castillo and Bouwman (2008) similarly describe PU as the extent to which humans trust that a certain electronic system will aid them to perform their work in an easier manner, efficiently and with good quality. It can be considered as a key variable that helps bank employees, as well as their clients to accept new technologies as they emerge as they help in providing them a 
greater degree of freedom when engaging in banking-related tasks such as transactions, expenditures etc. (Pikkarainen et al., 2004). Hanafizadeh et al. (2014) said that if an individual thinks that a certain technology will provide him with more advantages than its alternative being used before its invention, then he/she would find it more valuable and convenient. Due to efficiency, effectiveness, and benefits, the technology will be perceived as relatively more useful than that of its predecessor (Nassiwa, 2019).

\subsubsection{Perceived Ease of Use (PEOU)}

Davis (1989) describes perceived ease of use as the level to which a human trusts that making use of a certain system will be effortless to practice and consume. Davis (1993) describes it as the level to which an individual feels as if practicing that technological system will reduce one's stress, be it physical or mental. PEOU is an important determinant for acceptability of innovative and IT related devices and different researchers have supported this role of PEOU in relation to mobile commerce (Lin and Wang, 2005; Luarn and Lin, 2005; Teo et al., 2012), online banking (Lu et al., 2003; Tan et al., 2010; Wang, Wang, Lin and Tang, 2003), and wireless internet (Lu et al., 2003; Shih and Fang, 2004). Ease of use, in term of IT, is generally related to its complex inner workings that result in an easy-touse graphic user interface, easy surfing, effortless usage, and limited mental and physical effort. Hence, the more effortless a system is to practice and consume, the more usage of it will escalate performance (Venkatesh and Davis, 2000).

\subsubsection{Intention to Use (ITU)}

In the technology acceptance model, the intent towards usage of any specific technological system is directly related to the attitude that any individual shows towards the system and their perception that practicing the said system will benefit them and enhance their work productivity and output (Jackson, Chow, \& Leitch, 1997). Fishbein and Ajzen (1975) describe ITU as a measurement of the rigidity of one's intention to accomplish a certain task, i.e. using mobile banking system. Hogarth (1991) stated that an approach that can be used to understand the processes and constructs that lead an individual to either accept or reject a certain system is to focus attention to their attitudes towards it. Hence, Fishbein and Ajzen (1975) used this statement to develop their own theory that states that the best predictor of behavior (such as to use mobile banking) are intentions, and that these plans are influenced through a person's own attitudes and norm regarding the manners.

\subsection{Perceived Risk (PR)}

Pavlou (2001) describes perceived risk as an individual's belief that he is suffering a loss when chasing a favored goal. Gerrard and Barton Cunningham (2003) describe it as an uncertainty regarding the result of employing innovative devices. Püschel, Mazzon, \& Hernandez (2010) are of the opinion that customers normally think of risk because of the uncertainty regarding the degree of incon- 
sistency between what the customer judges about the technology and the real time behavior of the technology which is often not up to the customers' expectations. Consumers and service providers are both concerned about the quality of services being offered, online fraud and possible danger of criminal activities ( $\mathrm{Ba}$ and Pavlou, 2002). When talking specifically about mobile banking, considerable risk is involved which includes financial risk, public risk, time risk, risk associated with the provision of service, mental and emotional risk, and physical risk (Forsythe and Shi, 2003). In mobile banking, the risk is relatively greater than that of traditional banking due to the reason that most, if not all, of the transaction is being held online which makes it more susceptible to hacking and identity theft, which ultimately results in a considerable monetary and private loss of data (Yousafzai et al., 2003). It is the opinion of Laforet and Li (2005) that perceived risk is an important factor when it comes to the acquisition and use of new and innovative technology and devices. Riquelme and Rios (2010) also supported this fact stating that consideration of security is an important obstacle when thinking of adopting such platforms. The risks associated with using a mobile banking system is the same as those involved in internet banking since mobile banking is an enhanced version of it (Lee, Kozar and Larsen, 2003). Even though many risks involved mirror that of internet banking, there is considerably more risk involved in mobile banking when thinking in terms of personal loss, identity theft and loss of daily transactions (Riquelme and Rios, 2010). Therefore, all these risks eventually dissuade a person from using mobile banking system for their day-to-day transactions (Meuter et al., 2005). Luo et al. (2010) are of the opinion that such high risks and high stakes involved in transactions lead a person to develop negative notions regarding using and adopting the mobile banking system.

\section{Research Methodology}

\subsection{Conceptual Framework}

In an attempt to measure the effect of perceived usefulness, perceived ease of use, perceived risk and intention to use on the actual usage of mobile banking system, we propose the conceptual model below Figure 1. This model also shows the mediating role of ITU.

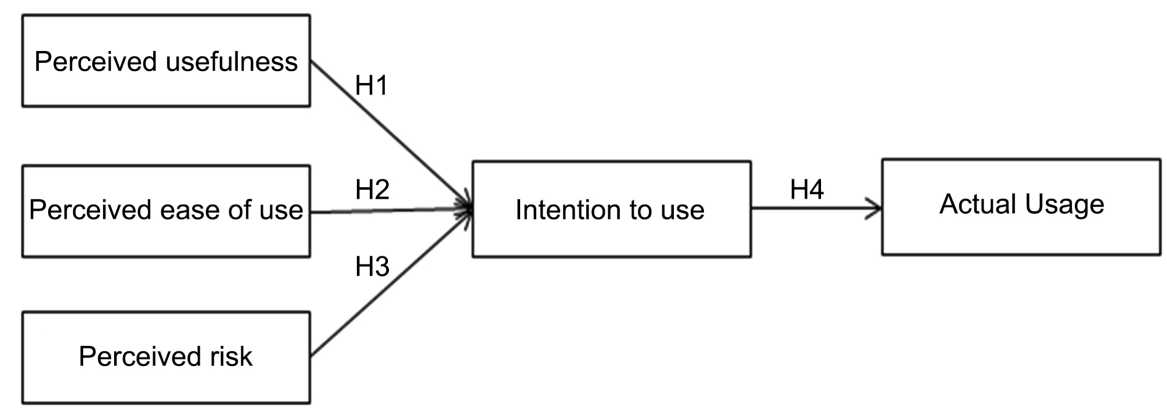

Figure 1. Hypothetical framework. 
The TAM2 model consists of four variables i.e. PU, PEOU, ITU and AU. In this model, intention to use acts as a mediating variable between perceived usefulness, perceived ease of use and actual usage. We have also added perceived risk to the model in order to better analyze the risks associated with the digital platforms. This will help us in understanding the behavior or individuals and how it affects their intention to use digital platforms for their banking.

\subsubsection{Perceived Usefulness and Intention to Use}

Venkatesh and Davis (2000) are of the opinion that PU is a key determinant for intention to use any technological system. A number of researches have been conducted that show that PU led to the usage of computer systems ( $\mathrm{Ha}$ and Stoel, 2009; Huang, 2008; Singh et al., 2010). Hanafizadeh et al. (2014) are of the opinion that the planning of making use of a certain system for transactional purposes is directly related to how an individual perceives its use. If a consumer thinks that using a certain technology will provide him with more benefits than the cost to use it, they intend to use that system. In a study conducted by Akturan and Tezcan (2012), the researchers stated that perceived usefulness had an effect upon the attitude of the consumer regarding mobile banking and that this attitude further affected the plan to accept and embrace the mobile banking system in the consumers. Another researcher in his study said that perceived usefulness was accepted as the primary precursor for the intention to start using the services of mobile banking in Malaysia (Amin, Baba and Muhammad, 2007). Hence the more useful mobile banking is perceived by consumers, the more their intention will be to use it. This leads us to our first hypothesis:

$\mathrm{H} 1$ : Perceived usefulness is a significant determinant of intention to use.

\subsubsection{Perceived Ease of Use and Intention to Use}

The PEOU of a certain technology does not make it necessarily easy to use but it is only a perception that favors adoption of that technology (Tan et al., 2014). Multiple studies have shown that if a perception of an individual regarding a certain system is that it is easy to use, then it promotes their intention to use said system. This research aims to study this relationship in terms of mobile banking. Another research that was conducted by Chitungo and Munongo (2013), they agreed that PEOU had an effect on the attitude of the users which led to their intention to make use of the services of mobile banking platforms. Cheah et al. (2011) agreed as well that there was a significant correlation among PEOU and ITU of mobile banking in Malaysia. Other studies performed in different countries also reinforced this relationship (Lule, Omwansa and Waema, 2012; Curran and Meuter, 2005). This leads to our second hypothesis:

H2: Perceived ease of use is a significant determinant of intention to use.

\subsubsection{Perceived Risk and Intention to Use}

Whether an individual uses a certain technological system or not can be influenced by security and privacy i.e. the degree of risks that is involved in using the 
system (Nassiwa, 2019). When it comes to mobile banking, PR was the key difficulty found to affect the intention of an individual to use this system (Ramdhony and Munien, 2013; Cho, 2004). The theory of perceived risk has been the topic of discussion since the 1980's to determine the behavior of the consumer when it comes to decision making (Taylor, 1974). PR is an important variable due to its relation with security and privacy concerns, which include loss of financial data, identity theft, stolen PIN codes etc. (Poon, 2008). Moreover, this also correlates with a stolen mobile phone that has access to an individual's financial data (Coursaris, Hassanein and Head, 2003). Hence, this leads to our third hypothesis:

H3: Perceived risk is negatively related to intention to use.

\subsubsection{Intention to Use as a Mediating Variable}

A research undertaken by Davis (1989) stated that if any individual had the behavioral intention to use a certain system, then it would be positively significant with actually using it; and found that plan to use a certain system is a vital determinant of the consumer's behavior and that other variables tend to influence the actual usage indirectly through the lens of behavioral intention. Another study conducted by Hill, Smith and Mann (1987) also supported this claim stating that intentions are positively related to actions. Sheppard, Hartwick and Warshaw (1988) conducted many researches whose foundation was the theory of reasoned action (TRA) model and found an average correlation of 0.54 among intention to use and acting on that intention. DeSanctis (1983), using an expectancy theory framework, also stated that the motivation of an individual to use a certain system is correlated with that individual actually using the system later on. Therefore, the literature suggests that ITU is a key element in implementing an actual system usage. This brings to our fourth, fifth, sixth, and seventh hypothesis:

\section{H4: Intention to use is a significant determinant of actual usage.}

When an individual believes that mobile banking system is useful and will help them in being efficient and productive, and then they are more likely to make an intention of using it, thereby increasing their chances of actually adopting the said system and using it in their daily lives. This relationship is shown in Figure 2.

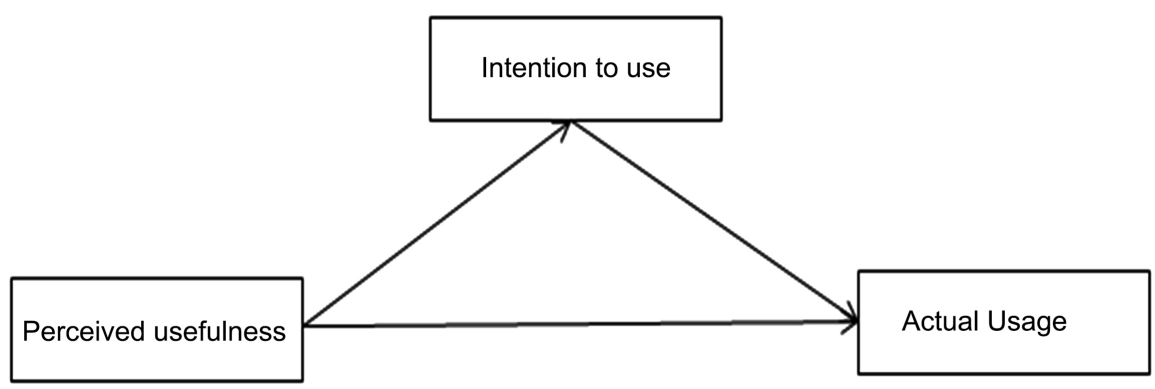

Figure 2. ITU as a mediating variable between PU and AU. 
H5: Intention to use acts as a significant mediator between perceived usefulness and actual usage.

The more an individual believes that a system is easy to use and perceives it in that fashion, the more they are likely to intend to use it and the more it will affect their actual adoption of the mobile banking system. This relationship is shown in Figure 3.

H6: Intention to use acts as a significant mediator between perceived ease of use and actual usage.

Considerable risk is involved in any kind of digital platform. The more the risk is involved in mobile banking, the more a person becomes reluctant in using that system; thereby leading to not using the system at all. This relationship is shown in Figure 4.

H7: Intention to use acts as a negative mediator between perceived risk and actual usage.

\subsubsection{Questionnaire Design and Measures}

1) Perceived Usefulness

The scale for PU was drawn from Venkatesh and Davis (2000). This scale encompassed four items for perceived usefulness. These items were analyzed through a 7-point Likert scale that had response anchors from $1=$ Highly Disagree to $7=$ Highly Agree. Individuals rating a higher number on this scale indicated that they perceive the mobile banking system to be of use to them and help them in improving their performance whether $s$ an employee or as a consumer.

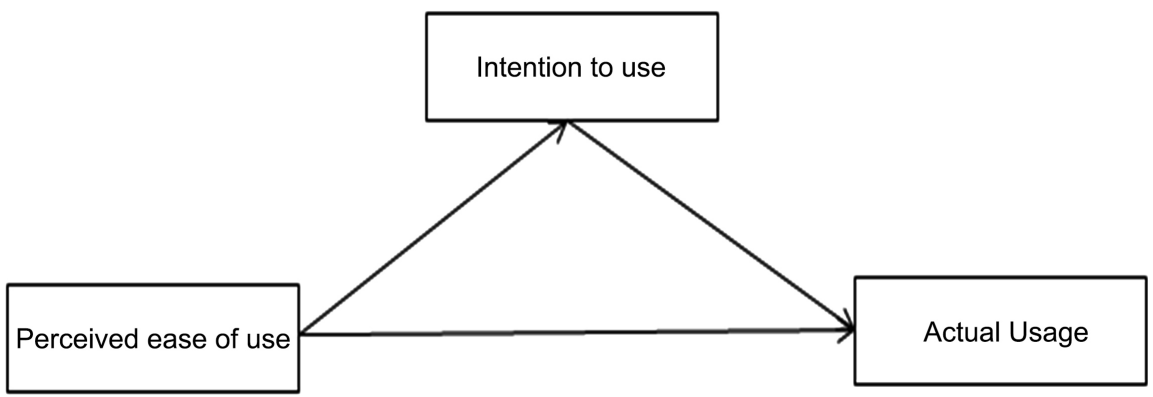

Figure 3. ITU as a mediating variable between PEOU and AU.

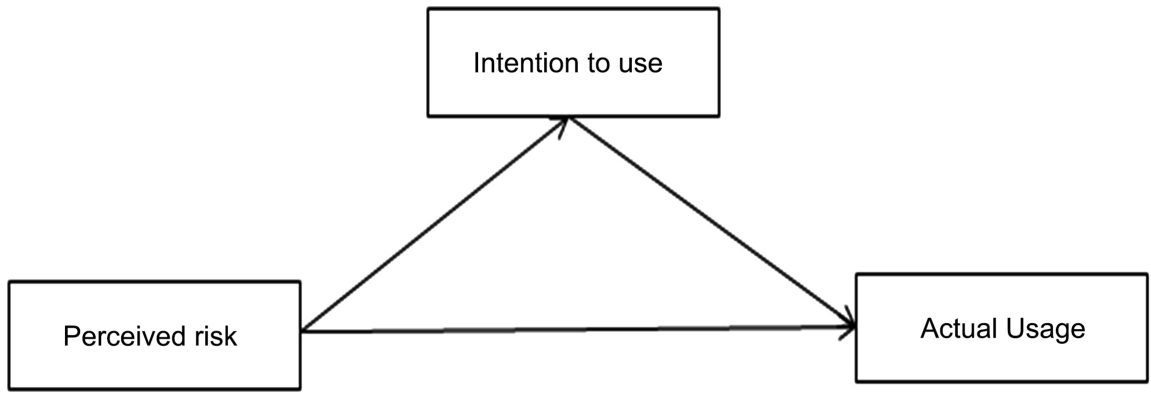

Figure 4. ITU as a mediating variable between PR and AU. 


\section{2) Perceived Ease of Use}

The scale for PEOU was drawn from Venkatesh and Davis (2000). This scale encompassed four items for perceived ease of use. These items were analyzed though a 7-point Likert scale with response anchors from $1=$ Highly Disagree to $7=$ Highly Agree. Individuals rating a higher number on this scale indicated that they feel that using services of mobile banking application will reduce their physical and mental stress, and will be effortless to use.

3) Perceived Risk

The scale for PR was drawn from Wu and Wang (2005). This scale encompassed four items for perceived risk. These items were analyzed through a 7-point Likert scale with response anchors from $1=$ Highly Disagree to $7=$ Highly Agree. Individuals rating a higher number on this scale indicated that using mobile banking system is particularly risky and are afraid of their personal and financial loss.

4) Intention to Use

The scale for ITU was drawn from Venkatesh and Davis (2000). This scale consisted of two items for intention to use. These items were analyzed through a 7 -point Likert scale with response from $1=$ Highly Disagree to $7=$ Highly Agree. Individuals rating a higher number on this scale indicated that they had a strong motivation to use the mobile banking system.

5) Actual Usage

The scale for actual usage was drawn from Wu and Wang (2005). This scale consisted of one item for actual usage. This item was measured on a 7-point Likert scale with response anchors from $1=$ Not Very Often to $7=$ Very Often. Individuals rating a higher number on this scale indicated that they are habitual and consistent users of mobile banking software.

\section{Results and Discussion}

The demographic characteristics of the respondents are given below in Table 1.

\subsection{Reliability of Study}

The reliability of study is shown in Table 2 .

For a questionnaire to be reliable, all items indicated in the questionnaire should be able to consistently measure their respective attribute (Hinton, 2014). Several researchers such as (Adamson \& Prion, 2013; Devon et al., 2007) have indicated that Cronbach's alpha is the most common reliability measure used by many researchers to estimate internal consistency reliability. Therefore we used Cronbach's alpha measure to estimate the reliability of the questionnaire used for this study. According to Bland \& Altman (1997), a Cronbach's a coefficient of 0.70 and above indicates a good and acceptable reliability measure. Results shown in Table 2 reveal that the estimated Cronbach's alpha measures are accepted, indicating the reliability of the questionnaire used for our study. 
Table 1. Demographic characteristics of respondents.

\begin{tabular}{|c|c|c|c|c|}
\hline Attribute & Frequency & Percent & Valid Percent & Cumulative Percent \\
\hline \multicolumn{5}{|l|}{ Gender } \\
\hline Male & 143 & 58.40 & 58.40 & 58.40 \\
\hline Female & 102 & 41.60 & 41.60 & 100.00 \\
\hline Total & 245 & 100.00 & 100.00 & \\
\hline \multicolumn{5}{|c|}{ Academic Qualification } \\
\hline No college degree & 27 & 11.00 & 11.00 & 11.00 \\
\hline Diploma & 64 & 26.10 & 26.10 & 37.10 \\
\hline Bachelor's degree & 118 & 48.20 & 48.20 & 85.30 \\
\hline Master's degree & 28 & 11.40 & 11.40 & 96.70 \\
\hline Ph.D. & 8 & 3.30 & 3.30 & 100.00 \\
\hline Total & 245 & 100.00 & 100.00 & \\
\hline \multicolumn{5}{|l|}{ Age } \\
\hline $16-20$ & 7 & 2.90 & 2.90 & 2.90 \\
\hline $21-25$ & 48 & 19.60 & 19.60 & 22.40 \\
\hline $26-30$ & 114 & 46.50 & 46.50 & 69.00 \\
\hline $31-35$ & 51 & 20.80 & 20.80 & 89.80 \\
\hline $36-40$ & 14 & 5.70 & 5.70 & 95.50 \\
\hline$>40$ & 11 & 4.50 & 4.50 & 100.00 \\
\hline Total & 245 & 100.00 & 100.00 & \\
\hline \multicolumn{5}{|l|}{ Adopted Item } \\
\hline Basic Phone & 9 & 3.70 & 3.70 & 3.70 \\
\hline Smart Phone & 190 & 77.60 & 77.60 & 81.20 \\
\hline 3G Phone & 38 & 15.50 & 15.50 & 96.70 \\
\hline PDA & 8 & 3.30 & 3.30 & 100.00 \\
\hline Total & 245 & 100.00 & 100.00 & \\
\hline \multicolumn{5}{|c|}{ Mobile Banking Experience } \\
\hline Yes & 158 & 64.50 & 64.50 & 64.50 \\
\hline No & 87 & 35.50 & 35.50 & 100.00 \\
\hline Total & 245 & 100.00 & 100.00 & \\
\hline
\end{tabular}

Table 2. Reliability table.

\begin{tabular}{ccc}
\hline Variable & No of Items measured & Cronbach's Alpha \\
\hline Perceived Usefulness (PU) & 4 & 0.919 \\
Perceived Ease of Use (PEOU) & 4 & 0.935 \\
Perceived Risk (PR) & 4 & 0.902 \\
Intention to Use (IU) & 2 & 0.892 \\
\hline
\end{tabular}




\subsection{Construct Validity}

Table 3 shows the construct validity test.

We performed a factor analysis test to establish the construct validity of our questionnaire. The estimates of the Kaiser-Meyer-Olkin (KMO) and Bartlett's Test of Sphericity were used to determine if the validity of our construct was achieved. The KMO measures the adequacy of the responses from the survey. Kaiser (1974) proposed a minimum acceptable KMO value of 0.5 to be achieved before a satisfactory factor analysis can be performed. The Bartlett's Test of Sphericity measures the strength of the relationship among the variables. A non-significant $P$-value means that "The correlation matrix is an identity matrix". Results in Table 3 show that the minimum KMO value was achieved $(\mathrm{KMO}=0.833)$ and a statistical significance was also achieved for the Bartlett's Test of Sphericity ( $\mathrm{P}$-value $=0.00$ ) indicating that the correlation matrix is not and identity matrix. This is an indication that all conditions for factor analysis have been achieved. The factor analysis results show that a total of 3 factors were extracted and the variance proportions of each of the factors were satisfactory. The 3 factors extracted explained $74.52 \%$ of the variance (or Variations).

\subsection{Pearson's Correlation}

Pearson's correlation is shown in Table 4 below.

According to Rodgers \& Nicewander (1988) the statistical association that exists between two continuous or quantitative variables can be measured by using Pearson's correlation coefficient statistic $(\rho)$. This test statistic uses the method of covariance to measure the relationship between two continuous variables of interest by providing the magnitude and the direction of the relationship (Wackerly et al., 2008). Mukaka (2012) and Overholser \& Sowinski (2008) proposed general cut-off values for judging the magnitude and direction of the correlation coefficients as: a correlation coefficient between $0.00-0.10$ and between $0.10-0.39$ indicates negligible correlation and a weak correlation respectively. A correlation coefficient between $0.40-0.69$ is an indication of a moderate association whereas a correlation coefficient between $0.70-0.89$ indicates a strong correlation and a correlation coefficient between $0.90-1.00$ indicates a very strong correlation. Table 4 shows that most of the variables are significantly correlated with each other while some relations are non-significant.

Table 3. Construct validity test.

\begin{tabular}{ccc}
\hline Test & Measure & Estimate \\
\hline Kaiser-Meyer-Olkin Measure of Sampling Adequacy & & 0.833 \\
Bartlett's Test of Sphericity & Approx. Chi-square & 3262.447 \\
& df & 105 \\
& Sig. & 0.00 \\
\hline
\end{tabular}


Table 4. Correlation matrix.

\begin{tabular}{|c|c|c|c|c|c|c|c|}
\hline \multirow{2}{*}{ Variable } & \multicolumn{7}{|c|}{ Correlation Matrix } \\
\hline & Mean & Std. Dev & 1 & 2 & 3 & 4 & 5 \\
\hline Actual usage (AU) & 4.62 & 2.20 & 1 & & & & \\
\hline Intention to use (IU) & 23.10 & 5.59 & $\begin{array}{l}0.389^{* *} \\
(0.000)\end{array}$ & 1 & & & \\
\hline $\begin{array}{l}\text { Perceived Usefulness } \\
\text { (PU) }\end{array}$ & 21.76 & 6.66 & $\begin{array}{l}0.351^{* *} \\
(0.000)\end{array}$ & $\begin{array}{l}0.605^{* *} \\
(0.000)\end{array}$ & 1 & & \\
\hline $\begin{array}{l}\text { Perceived Ease of Use } \\
\text { (PEOU) }\end{array}$ & 16.71 & 7.55 & $\begin{array}{l}0.615^{\star *} \\
(0.000)\end{array}$ & $\begin{array}{l}0.534^{* *} \\
(0.000)\end{array}$ & $\begin{array}{l}0.560^{* *} \\
(0.000)\end{array}$ & 1 & \\
\hline Perceived Risk (PR) & 12.00 & 2.96 & $\begin{array}{c}0.020 \\
(0.753)\end{array}$ & $\begin{array}{l}-0.105^{*} \\
(0.013)\end{array}$ & $\begin{array}{l}-0.147^{*} \\
(0.022)\end{array}$ & $\begin{array}{c}0.087 \\
(0.173)\end{array}$ & 1 \\
\hline
\end{tabular}

${ }^{*}$ Correlation is significant at the 0.01 level (2-tailed). $P$-values in parenthesis; ${ }^{*}$ Correlation is significant at the 0.05 level (2-tailed).

\subsection{Regression Analysis}

The result for model summary of the multiple linear regression analysis is presented in Table 5. The multiple coefficient (R) and coefficient of determination $\left(R^{2}\right)$ were estimated to be 0.653 and 0.426 respectively. The $R^{2}$ indicates the extent of variation in the dependent variable caused by the independent variables. This indicates that about $42.6 \%$ of the difference in the dependent variable is attributed to the independent variables while the rest of the variations are attributed to the error term. The F-test, which is an indication of model fit, was found to be significant at the $95 \%$ confidence level with an estimate and P-value of 59.607 and 0.000 respectively. This indicates a good and acceptable model fit. The autocorrelation in our model was found to be relatively normal and acceptable with a Durbin-Watson value of 1.840 (Field, 2009).

Table 6 depicts the ANOVA table and explains the sources and degree of variations in our model. It also provides information about the tests of significance and model fit. Result in Table 6 reveals that the P-value for the ANOVA test was less than 0.05 at the $95 \%$ confidence level, hence statistically significant. This further indicates a good and acceptable model fit.

The $\beta$-estimates or coefficient of our regression analysis are presented in $\mathrm{Ta}$ ble 7. The result shows that Perceived Usefulness (PU) and Perceived Ease of Use (PEOU) were statistically significant at the $95 \%$ confidence level; and impact positively on Intention to Use (IU) with $\beta$-estimates of 0.226 and 0.133 respectively. Perceived Risk (PR) was found to impact negatively on Intention to Use (IU) with a $\beta$-estimate of -0.027 , however, this association was also found to be significant at the $95 \%$ confidence level $(P<0.05)$. 
Table 5. Model summary.

\begin{tabular}{cc}
\hline Measure & Estimate \\
$\mathrm{R}$ & 0.653 \\
R-square & 0.426 \\
Adjusted R-square & 0.419 \\
Standard Error of estimate & 2.25616 \\
F-change & 59.607 \\
Sig. F & 0.000 \\
Durbin-Watson & 1.840 \\
\hline
\end{tabular}

Dependent variable: IU; Predictors: Constant, PU, PEOU, and PR.

Table 6. ANOVA table.

\begin{tabular}{cccccc}
\hline Model & Sum of squares & df & Mean square & F & Sig \\
\hline Regression & 910.247 & 3 & 303.416 & 59.607 & 0.000 \\
Residual & 1226.749 & 241 & 5.090 & & \\
Total & 2136.996 & 244 & & & \\
\hline
\end{tabular}

Dependent variable: IU; Predictors: Constant, PU, PEOU, PR.

Table 7. Table of coefficient.

\begin{tabular}{cccccc}
\hline Variables & Estimate & T Value & Sig. Value & Tolerance & VIF \\
\hline Constant & 4.320 & 5.811 & 0.000 & & \\
Perceived Usefulness & 0.226 & 7.044 & 0.000 & 0.647 & 1.545 \\
Perceived Ease of Use & 0.133 & 4.982 & 0.000 & 0.657 & 1.523 \\
Perceived Risk & -0.027 & -1.985 & 0.048 & 0.937 & 1.068 \\
\hline
\end{tabular}

Dependent variable: Intention to use (IU).

Following the recommendations of Daoud (2017) and Ringle et al. (2015), we found no presence of multicollinearity in our data. These researchers proposed a minimum acceptable value of VIF to be 5 and a tolerance value of above 0.10 to have no multicollinearity in data set. The fitted model based on the estimated $\beta$-estimates in Table 7 is presented below:

$$
\mathrm{IU}=4.320+0.226(\mathrm{PU})+0.133(\mathrm{PEOU})-0.027(\mathrm{PR})
$$

where:

Dependent variable: Intention to use (IU).

Predictor variables: Perceived Usefulness.

Perceived Ease of Use (PEOU).

Perceived Risk (PR). 


\subsection{Process Analysis}

We performed a multiple linear regression analysis using Andrews F. Hayes process macro (version 3.5) to examine the mediating effect of Intention to use (IU) on Perceived Usefulness (PU), Perceived Ease of Use (PEOU), Perceived Risk (PR), and Actual Usage (AU). The results for the process analysis are presented in Table 8 and Table 9.

Table 8 shows the direct effect of PU, PEOU, and PR on AU. The result revealed a significant positive direct relationship between PU, PEOU and actual Usage (AU) and a non-significant positive relationship between PR and AU $(P$-value $>0.05)$ at the $95 \%$ confidence level. The corresponding T-values for PU, PEOU are above the acceptable value of 1.96 while that of PR is less than the acceptable value $(\mathrm{T}$-value $=1.0359)$.

Table 9 presents the indirect effects or relationships between PU, PEOU, PR and AU as mediated by Intention to Use (IU). The result revealed a significant association between the dependent variable (AU) and the independent variables (PU, PEOU, PR) since zero (0) lies outside the respective confidence intervals. We found out that, the direct effect of PR on AU was positive and non-significant, however when Intention to Use (IU) mediated the relationship between PR and $\mathrm{AU}$, the effect becomes negative and significant at the $95 \%$ confidence interval because zero lies outside the confidence region of the effect $(0.1019,0.0108)$.

\subsection{Hypothesis Testing}

\section{H1: Perceived usefulness is a significant determinant of intention to use.}

Table 8. Direct effect of PU, PEOU, PR on AU.

\begin{tabular}{cccccc}
\hline $\begin{array}{c}\text { Dependent } \\
\text { variable (Y) }\end{array}$ & $\begin{array}{c}\text { Independent } \\
\text { variable (X) }\end{array}$ & $\begin{array}{l}\text { Direct } \\
\text { Effect }\end{array}$ & SE & t-value & $P$-value \\
\hline PU & 0.0718 & 0.0289 & 2.4833 & 0.0137 \\
AU & PEOU & 0.1882 & 0.0197 & 9.5387 & 0.0000 \\
& PR & 0.0179 & 0.0173 & 1.0359 & 0.3013 \\
\hline
\end{tabular}

Table 9. Indirect Effects of IU on PU, PEOU, PR and AU.

\begin{tabular}{ccccccc}
\hline $\begin{array}{c}\text { Mediator } \\
(\mathrm{M})\end{array}$ & $\begin{array}{c}\text { Independent } \\
\text { variable (X) }\end{array}$ & $\begin{array}{c}\text { Dependent } \\
\text { variable (Y) }\end{array}$ & $\begin{array}{c}\text { Standardized } \\
\text { indirect } \\
\text { Effect }\end{array}$ & BootSE & BootLLCI & BootULCI \\
\hline & PU & & 0.1687 & 0.0447 & 0.0766 & 0.2521 \\
IU & PEOU & AU & 0.0455 & 0.0305 & 0.0112 & 0.1097 \\
& PR & & -0.0413 & 0.0286 & 0.0108 & 0.1019 \\
\hline
\end{tabular}


Perceived usefulness (PU) was estimated to have a $\beta$-estimate of 0.226 . This means that, the impact of PU on predicting Intention to Use (IU) is about $23 \%$ and this impact is statistically significant with a $P$-value of $0.000(P<0.05)$. The corresponding $\mathrm{T}$-value is also statistically significant at the $95 \%$ confidence level (T-value $>1.96$ ). Result in Table 4 also indicates a strong positive correlation between Perceived Usefulness (PU) and Intention to Use (IU) with a correlation coefficient $(\rho)$ of 0.605 . This relationship is also significant at the $99 \%$ confidence interval with a $P$-value of 0.000 . This means that, when people perceived that a certain electronic system or technology can aid them to perform their tasks in an easier and efficient process, they will make use of that technology, Hanafizadeh et al. (2014) asserts that if an individual perceives that the use of a certain technology or system can enhance his performance and an increase in competitive advantage than its alternative being used, the individual will go for the new technology. How an individual or an organization perceives the usefulness of a technology can influence their intention to use that technology. Therefore we accept our hypothesis based on our analysis above and conclude that, Perceived Usefulness is a significant determinant of Intention to Use a mobile banking technology.

H2: Perceived Ease of Use (PEOU) is a significant determinant of Intention to Use (IU).

How easy it is to use a certain technology can influence consumers or organizations intentions to use that technology. Result in Table 7 shows that PEOU has a significant positive impact on Intention to Use $(\beta=0.133, P$-value $=$ 0.000 ). The estimated T-value is 4.982 , which is greater than the critical value of 1.96 indicating statistical significance at the $95 \%$ confidence interval. Table 4 shows a moderate correlation between PEOU and IU with an estimated correlation coefficient $(\rho)$ of 0.534 . This relationship was statistically significant at the 99\% confidence level with a $P$-value of 0.000 . PEOU has the tendency to influence an individual's intention to use a certain technology. Several researchers such as (Tan et al., 2014; Curran \& Menter, 2005; Cheah et al., 2011) have revealed the significant association between PEOU and organization's or consumer's intention to use or to adopt a certain technology. Consequently, we accept our hypothesis and conclude that PEOU is a significant determinant of Intention to Use.

H3: Perceived Risk (PR) is negatively related to Intention to Use (IU).

Perceived risk is estimated to have a negative impact on Intention to Use as shown in Table 7. The effect of Perceived risk on Intention to use is estimated to be $\beta=-0.027$ with a corresponding $P$-value of 0.048 indicating statistical significance at the $95 \%$ confidence interval. The corresponding T-value is also significant with a value of -1.985 (T-value $>-1.96$ ). The correlation matrix in Table 4 indicates a weak negative relationship between PR and IU. This association is significant at the $95 \%$ confidence level with a $P$-value of 0.013 . The degree of risks that is involved in using a certain technology can actually influence con- 
sumers or organizations intention to use that particular technology (Ramdhony \& Munien, 2013; Cho, 2004). As a result, we accept our hypothesis and conclude that Perceived Risk is negatively related to Intention to Use.

H4: Intention to Use (IU) is a significant determinant of Actual Usage (AU).

The correlation strength $(\rho)$ between Intention to Use and Actual Usage is estimated to be 0.389 indicating a nearly moderate positive relationship between the two variables. The relationship between IU and AU was statistically significant at the $99 \%$ confidence interval with a P-value of 0.000 . This means that, individuals with high level of intention to use a certain technology will actually use that technology. Hill et al. (1987) corroborated this result and assert that Intentions are positively related to actions. As a result, we accept our hypothesis and conclude that, Intention to Use is a significant determinant of Actual Usage.

H5: Intention to Use (IU) acts a significant mediator between Perceived usefulness (PU) and Actual Usage (AU).

Results in Table 9 indicate a significant mediating effect of Intention to Use between PU and AU. The direct effect of PU on AU is estimated to be 0.0718 . This effect was statistically significant with a $P$-value of 0.0137 and a corresponding T-value of 2.4833. The indirect effect; which represents the mediating effect of IU between PU and AUI is estimated to be 0.1687 as shown in Table 9 . The indirect effect is estimated to have a Boot standard error (BootSE) value of 0.0447, Boot Lower Level Confidence Interval (BootLLCI) value of 0.0766 and Boot Upper Level Confidence Interval (BootULCI) value of 0.2521. This effect is statistically significant since zero (0) lies outside the estimated confidence interval $(0.0766,0.2521)$. Consequently, we accept our hypothesis and conclude that, Intention to Use acts as a significant mediator between Perceived Usefulness (PU) and Actual usage (AU).

H6: Intention to Use (IU) acts a significant mediator between Perceived Ease of Use (PEOU) and Actual Usage (AU).

The direct effect of PEOU on Actual Usage is estimated to be positive and statistically significant with a $P$-value of 0.0000 . The estimated effect size of PEOU on $\mathrm{AU}$ is estimated to be 0.1882 with a standard error of 0.0197 and a corresponding significant T-value of 9.5387 as shown in Table 9. The mediating effect of IU between PEOU and AU reveals a standardized indirect effect of 0.0455 with a Boot standard error (BootSE) value of 0.0305, Boot Lower Level Confidence Interval (BootLLCI) and Boot Upper Level confidence Interval (BootUL$\mathrm{CI})$ values of 0.0112 and 0.1097 respectively. Zero (0) lies outside the estimated confidence intervals $(0.0112,0.1097)$ indicating that, the mediating effect of IU between PEOU and AU is statistically significant at the $95 \%$ confidence interval. Hence we support our hypothesis and conclude that, intention to use acts as a significant mediator between Perceived Ease of Use (PEOU) and Actual Usage (AU).

H7: Intention to use acts as a negative mediator between Perceived Risk 


\section{(PR) and Actual Usage (AU).}

The estimated direct effect of Perceived risk (PR) on Actual Usage (AU) is 0.0179 and a standard error of 0.0173 . This effect was not significant at the $95 \%$ confidence interval with the P-value greater than the accepted value of 0.05 and T-value less than the accepted value of 1.96. The mediating effect of IU between $\mathrm{PR}$ and AU reveals a significant negative association between PR and AU. This negative standardized indirect effect is estimated to be -0.0413 with a Boot standard error (BootSE) of 0.0286. The Boot Lower Level Confidence Interval (BootLLCI) and Boot Upper Level Confidence Interval (BootULCI) are estimated to be 0.0108 and 0.1019 respectively. Since zero (0) lies outside the estimated confidence region, the indirect or mediating effect of IU between PR and AU is statistically significant. Therefore we support our hypothesis and conclude that Intention to Use (IU) acts as a negative mediator between Perceived Risk (PR) and Actual Usage (AU).

\section{Conclusion}

This study was conducted to analyze the effect of perceived usefulness, perceived ease of use, perceived risk, and intention to use on actual usage of mobile banking adoption. We made use of the technology acceptance model (TAM2) for research purposes with an additional variable of perceived risk. This research was specifically conducted in Uganda to study the banking behavior of bank employees as well as their clients. This study corroborates the entire hypothesis developed and we found no conflict of interest.

Our study proves that if an individual perceives that using a mobile banking system will be useful, and help them in their productivity and outcome, then they will be more motivated to use it. This motivation will eventually lead to their actual usage of the mobile banking system. Moreover, the perceived ease of use also plays an important part in adoption of mobile banking. This study concluded that if people think that mobile banking system is easy to use and it will save them the mental as well as the physical effort of going to the bank in person, then they will definitely think of using it. These benefits will also lead to actual usage of the system. Along with a lot of its benefits, mobile banking is not perfect. It comes with a number of disadvantages as well such as identity theft, financial loss, losing credentials etc. Therefore, there is considerable risk involved in using this application. Our research found that this risk poses a threat in the mind of the consumers and has a negative effect upon their intention of using the said application, hence deterring them from using it. It is only when the advantages outweigh the disadvantages that the consumers decide to use the mobile banking system. Furthermore, our research found that the intention to use was a significant mediator between perceived usefulness, perceived ease of use, and actual usage of mobile banking, where it acted as a negative mediator between perceived risk and actual usage.

Therefore, our research can aid the banking industry of Uganda if they decide 
to launch a mobile banking application. This study can provide them insights on what characteristics would make the usage of the system more attractive and what things to avoid to increase its marketability, such as the banking industry could make its user interface easier to use and put up as many safety features as they can to ensure that the risk of using such system would be minimal. Moreover, this research also provides guidance to the clients of the banks and would help them in deciding whether they want to use the application or not. It clearly shows its risks as well as its advantages for easy decision making.

This study, like any other, is not without its limitations. This study was conducted in a cross-sectional manner and did not make use of the most recent technology acceptance model. Moreover, all the questions that the candidates were asked to respond to were closed-ended. Moreover, the respondents' pool was relatively narrow since it was focused on Uganda. Future researchers can add to this research by choosing to conduct a longitudinal research and using a qualitative method to get further insights from the clients. Moreover, future study could be conducted on an international basis to get a more diverse pool of respondents. Furthermore, recent models of technology acceptance models can be used and can be paired with additional variables to get a deeper understanding about the mobile banking adoption.

\section{Conflicts of Interest}

The authors declare no conflicts of interest regarding the publication of this paper.

\section{References}

Adamson, K. A., \& Prion, S. (2013). Reliability: Measuring Internal Consistency Using Cronbach's a. Clinical Simulation in Nursing, 9, e179-e180. https://doi.org/10.1016/j.ecns.2012.12.001

Akturan, U., \& Tezcan, N. (2012). Mobile Banking Adoption of the Youth Market: Perceptions and Intentions. Marketing Intelligence \& Planning, 30, 444-459. https://doi.org/10.1108/02634501211231928

Amin, H., Baba, R., \& Muhammad, M. Z. (2007). An Analysis of Mobile Banking Acceptance by Malaysian Customers. Sunway University College Academic Journal, 4, 1-12.

Ba, S., \& Pavlou, P. (2002). Evidence of the Effect of Trust Building Technology in Electronic Markets: Price Premiums and Buyer Behavior. MIS Quarterly, 26, 243-268. https://doi.org/10.2307/4132332

Barnes, S. J., \& Corbitt, B. (2003). Mobile Banking: Concept and Potential. International Journal of Mobile Communications, 1, 273-288.

https://doi.org/10.1504/IJMC.2003.003494

Bland, J. M., \& Altman, D. G. (1997). Statistics Notes: Cronbach’s Alpha. BMJ, 314, 572. https://doi.org/10.1136/bmj.314.7080.572

Cheah, C. M., Teo, A. C., Sim, J. J., Oon, K. H., \& Tan, B. I. (2011). Factors Affecting Malaysian Mobile Banking Adoption: An Empirical Analysis. International Journal of Network and Mobile Technologies, 2, 149-160.

Chen, L.-D., Gillenson, M. L., \& Sherrell, D. L. (2002). Enticing Online Consumers: An 
Extended Technology Acceptance Perspective. Information \& Management, 39, 705-719. https://doi.org/10.1016/S0378-7206(01)00127-6

Chitungo, S. K., \& Munongo, S. (2013). Extending the Technology Acceptance Model to Mobile Banking Adoption in Rural Zimbabwe. Journal of Business Administration and Education, 3, 51-79.

Cho, J. (2004). Likelihood to Abort an Online Transaction: Influences from Cognitive Evaluations, Attitudes, and Behavioral Variables. Information \& Management, 41, 827-838. https://doi.org/10.1016/j.im.2003.08.013

Coursaris, C., Hassanein, K., \& Head, M. (2003). M-Commerce in Canada: An Interaction Framework for Wireless Privacy. Canadian Journal of Administrative Sciences/Revue Canadienne des Sciences de l'Administration, 20, 54-73. https://doi.org/10.1111/j.1936-4490.2003.tb00305.x

Curran, J. M., \& Meuter, M. L. (2005). Self-Service Technology Adoption: Comparing Three Technologies. Journal of Services Marketing, 19, 103-113. https://doi.org/10.1108/08876040510591411

Daoud, J. I. (2017). Multicollinearity and Regression Analysis. Journal of Physics: Conference Series, 949, Article ID: 012009. https://doi.org/10.1088/1742-6596/949/1/012009

Davis, F. D. (1989). Perceived Usefulness, Perceived Ease of Use, and End User Acceptance of Information Technology. MIS Quarterly, 13, 319-340. https://doi.org/10.2307/249008

Davis, F. D. (1993). User Acceptance of Information Technology: System Characteristics, User Perceptions and Behavioral Impacts. International Journal of Man-Machine Studies, 38, 475-487. https://doi.org/10.1006/imms.1993.1022

DeSanctis, G. (1983). Expectancy Theory as an Explanation of Voluntary Use of a Decision Support System. Psychological Reports, 52, 247-261. https://doi.org/10.2466/pr0.1983.52.1.247

Devon, H. A., Block, M. E., Moyle-Wright, P., Ernst, D. M., Hayden, S. J., Lazzara, D. J., Savoy, S. M., \& Kostas-Polston, E. (2007). A Psychometric Toolbox for Testing Validity and Reliability. Journal of Nursing Scholarship, 39, 155-164. https://doi.org/10.1111/j.1547-5069.2007.00161.x

Field, A. P. (2009). Discovering Statistics Using SPSS: And Sex and Drugs and Rock ' $n$ ' Roll (3rd ed.). London: Sage.

Fishbein, M., \& Ajzen, I. (1975). Belief, Attitude, Intention, and Behavior: An Introduction to Theory and Research. Reading, MA: Addison-Wesley.

Forsythe, S. M., \& Shi, B. (2003). Consumer Patronage and Risk Perceptions in Internet Shopping. Journal of Business Research, 56, 867-875.

https://doi.org/10.1016/S0148-2963(01)00273-9

Gerrard, P., \& Barton Cunningham, J. B. (2003). The Diffusion of Internet Banking among Singapore Consumers. International Journal of Bank Marketing, 21, 16-28. https://doi.org/10.1108/02652320310457776

Ha, S., \& Stoel, L. (2009). Consumer E-Shopping Acceptance: Antecedents in a Technology Acceptance Model. Journal of Business Research, 62, 565-571. https://doi.org/10.1016/j.jbusres.2008.06.016

Hanafizadeh, P., Behboudi, M., Koshksaray, A. A., \& Tabar, M. J. S. (2014). Mobile-Banking Adoption by Iranian Bank Clients. Telematics and Informatics, 31, 62-78. https://doi.org/10.1016/j.tele.2012.11.001

Hill, T., Smith, N. D., \& Mann, M. F. (1987). Role of Efficacy Expectations in Predicting 
the Decision to Use Advanced Technologies: A Case of Computers. Journal of Applied Psychology, 72, 307-318. https://doi.org/10.1037/0021-9010.72.2.307

Hinton, P. R. (2014). Statistics Explained, Statistics Explained. London: Routledge. https://doi.org/10.4324/9781315797564

Hogarth, R. M. (1991). A Perspective on Cognitive Research in Accounting. The Accounting Review, 66, 277-290.

Huang, E. (2008). Use and Gratification in E-Consumers. Internet Research, 18, 405-426. https://doi.org/10.1108/10662240810897817

Igbaria, M., Zinatelli, N., Cragg, P., \& Cavaye, A. L. (1997). Personal Computing Acceptance Factors in Small Firms: A Structural Equation Model. MIS Quarterly, 21, 279-305. https://doi.org/10.2307/249498

Jackson, C. M., Chow, S., \& Leitch, R. A. (1997). Toward an Understanding of the Behavioral Intention to Use an Information System. Decision Sciences, 28, 357-389. https://doi.org/10.1111/j.1540-5915.1997.tb01315.x

Kaiser, H. F. (1974). An Index of Factorial Simplicity Psychometrics. Psychometrika, 39, 31-36. https://doi.org/10.1007/BF02291575

Koenig-Lewis, N., Palmer, A., \& Moll, A. (2010). Predicting Young Consumers' Take Up of Mobile Banking Services. International Journal of Bank Marketing, 28, 410-432. https://doi.org/10.1108/02652321011064917

Laforet, S., \& Li, X. (2005). Consumers' Attitudes towards Online and Mobile Banking in China. International Journal of Bank Marketing, 23, 362-380. https://doi.org/10.1108/02652320510629250

Lee, Y., Kozar, K. A., \& Larsen, K. R. (2003). The Technology Acceptance Model: Past, Present, and Future. Communications of the Association for Information Systems, 12, 50. https://doi.org/10.17705/1CAIS.01250

Legris, P., Ingham, J., \& Collerette, P. (2003). Why Do People Use Information Technology? A Critical Review of the Technology Acceptance Model. Information \& Management, 40, 191-204. https://doi.org/10.1016/S0378-7206(01)00143-4

Lin, H. H., \& Wang, Y. S. (2005). Predicting Consumer Intention to Use Mobile Commerce in Taiwan. Proceeding of the International Conference on Mobile Business (ICMB'05), Sydney, 11-13 July 2005, 406-412.

Lopez-Nicolas, A., Molina-Castillo, F. J., \& Bouwman, H. (2008). An Assessment of Advanced Mobile Services Acceptance: Contributions from TAM and Diffusion Theory Models. Information \& Management, 45, 359-364.

https://doi.org/10.1016/j.im.2008.05.001

Lu, J., Yu, C. S., Liu, C., \& Yao, J. E. (2003). Technology acceptance model for wireless internet. Internet Research, 13, 206-222. https://doi.org/10.1108/10662240310478222

Luarn, P., \& Lin, H. H. (2005). Toward an Understanding of the Behavioral Intention to Use Mobile Banking. Computer in Human Behaviour, 21, 873-891. https://doi.org/10.1016/j.chb.2004.03.003

Lule, I., Omwansa, T. K., \& Waema, T. M. (2012). Application of Technology Acceptance Model (TAM) in Mobile Banking Adoption in Kenya. International Journal of Computing and ICT Research, 6, 31-43.

Luo, X., Li, H., Zhang, J., \& Shim, J. P. (2010). Examining Multi-Dimensional Trust and Multi-Faceted Risk in Initial Acceptance of Emerging Technologies: An Empirical Study of Mobile Banking Services. Decision Support Systems, 49, 222-234.

https://doi.org/10.1016/j.dss.2010.02.008 
Mathwick, A., Malhotra, N. K., \& Rigdon, E. (2001). The Effect of Dynamic Retail Experiences of Value: An Internet and Catalog Comparison. Journal of Retailing, 78, 51-60. https://doi.org/10.1016/S0022-4359(01)00066-5

Meuter, M. L., Bitner, M. J., Ostrom, A. L., \& Brown, S. W. (2005). Choosing among Alternative Service Delivery Modes: An Investigation of Customer Trial of Self-Service Technologies. Journal of Marketing, 69, 61-83. https://doi.org/10.1509/jmkg.69.2.61.60759

Mukaka, M. M. (2012). Statistics Corner: A Guide to Appropriate Use of Correlation Coefficient in Medical Research. Malawi Medical Journal, 24, 69-71.

Nassiwa, J. (2019). Factors Affecting Adoption of Mobile Banking in Uganda: A Case Study of Stanbic Bank, Makerere University Branch. Doctoral Dissertation, Kampala: Makerere University.

Overholser, B. R., \& Sowinski, K. M. (2008). Biostatistics Preview: Part 2. Nutrition in Clinical Practice, 23, 76-84. https://doi.org/10.1177/011542650802300176

Pavlou, P. A. (2001). Integrating Trust in Electronic Commerce with the Technology Acceptance Model: Model Development and Validation. Proceedings of Seventh Americas Conference on Information Systems (AMCIS), December 2001, 816-822.

Peevers, G., Douglas, G., \& Jack, M. A. (2008). A Usability Comparison of Three Alternative Message Formats for an SMS Banking Service. International Journal of $\mathrm{Hu}$ man-Computer Studies, 66, 113-123. https://doi.org/10.1016/j.ijhcs.2007.09.005

Pikkarainen, T., Pikkarainen, K., Karjaluoto, H., \& Pahnila, S. (2004). Consumer Acceptance of Online Banking: An Extension of the Technology Acceptance Model. Internet Research, 14, 224-235. https://doi.org/10.1108/10662240410542652

Poon, W. C. (2008). Users' Adoption of E-Banking Services: The Malaysian Perspective. Journal of Business \& Industrial Marketing, 23, 59-69.

Porteous, D. (2006). The Enabling Environment for Mobile Banking in Africa. Boston MA: DFID.

Püschel, J., Mazzon, J. A., \& Hernandez, J. M. C. (2010). Mobile Banking: Proposition of an Integrated Adoption Intention Framework. International Journal of Bank Marketing, 28, 389-409. https://doi.org/10.1108/02652321011064908

Ramdhony, D., \& Munien, S. (2013). An Investigation on Mobile Banking Adoption and Usage: A Case Study of Mauritius. Proceedings of 3rd Asia-Pacific Business Research Conference, Kuala Lumpur, Malaysia, 25-26 February 2013.

Ringle, C. M., Wende, S., \& Becker, J.-M. (2015). SmartPLS 3. Bönningstedt: SmartPLS. http://www.smartpls.com

Riquelme, H. E., \& Rios, R. E. (2010). The Moderating Effect of Gender in the Adoption of Mobile Banking. International Journal of Bank Marketing, 28, 328-341. https://doi.org/10.1108/02652321011064872

Rodgers, J. L., \& Nicewander, W. A. (1988). Thirteen Ways to Look at the Correlation Coefficient. The American Statistician, 42, 59-66. https://doi.org/10.2307/2685263

Sheppard, B. H., Hartwick, J., \& Warshaw, P. R. (1988). The Theory of Reasoned Action: A Meta-Analysis of Past Research with Recommendations for Modifications for Future Research. Journal of Consumer Research, 15, 325-343. https://doi.org/10.1086/209170

Shih, Y. Y., \& Fang, K. (2004). The Use of a Decomposed Theory of Planned Behavior to Study Internet Banking in Taiwan. Internet Research, 14, 213-223. https://doi.org/10.1108/10662240410542643

Singh, S., Singh, D. K., Singh M. K., \& Singh, S. K. (2010). The Forecasting of 3G Market 
in India Based on Revised Technology Acceptance Model. International Journal of Next-Generation Networks, 2, 61-68. https://doi.org/10.5121/ijngn.2010.2206

Sulaiman, A., Jaafar, N. I., \& Mohezar, S. (2007). An Overview of Mobile Banking Adoption among the Urban Community. International Journal of Mobile Communications, 5, 157-168. https://doi.org/10.1504/IJMC.2007.011814

Tan, G. W. H., Chong, C. K., Ooi, K. B., \& Chong, A. Y. L. (2010). The Adoption of Online Banking in Malaysia: An Empirical Analysis. International Journal of Business and Management Science, 3, 169-193.

Tan, G. W. H., Ooi, K. B., Leong, L. Y., \& Lin, B. (2014). Predicting the Drivers of Behavioral Intention to Use Mobile Learning: A hybrid SEM-Neural Networks Approach. Computers in Human Behavior, 36, 198-213. https://doi.org/10.1016/j.chb.2014.03.052

Taylor, J. W. (1974). The Role of Risk in Consumer Behavior: A Comprehensive and Operational Theory of Risk Taking in Consumer Behavior. Journal of Marketing, 38, 54-60. https://doi.org/10.1177/002224297403800211

Taylor, S., \& Todd, P. (1995). Assessing IT Usage: The Role of Prior Experience. MIS Quarterly, 19, 561-570. https://doi.org/10.2307/249633

Teo, A. C., Cheah, C. M., Leong, L. Y., Hew, T. S., \& Shum, Y. L. (2012). What Matters Most in Mobile Payment Acceptance? A Structural Analysis. International Journal of Network and Mobile Technologies, 3, 49-69.

Turban, E., King, D., Viehland, D., \& Lee, J. (2006). Electronic Commerce 2006: A Management Perspective. Upper Saddle River, NJ: Prentice Hall.

Venkatesh, V., \& Davis, F. D. (2000). A Theoretical Extension of the Technology Acceptance Model: Four Longitudinal Field Studies. Management Science, 46, 186-204. https://doi.org/10.1287/mnsc.46.2.186.11926

Venkatesh, V., \& Morris, M. G. (2000). Why Don’t Men Ever Stop to Ask for Directions? Gender, Social Influence, and Their Role in Technology Acceptance and Usage Behavior. MIS Quarterly, 24, 115-139. https://doi.org/10.2307/3250981

Wackerly, D. D., Mendenhall III, W., \& Scheaffer, R. L. (2008). Multivariate Probability Distributions. In Mathematical Statistics with Applications (7th ed., pp. 223-295). Belmont, CA: Brooks/Cole.

Wang, Y. S., Wang, Y., Lin, Y. M., \& Tang, T. I. (2003). Determinants of User Acceptance of Internet Banking: An Empirical Study. International Journal of Service Industry Management, 14, 501-519. https://doi.org/10.1108/09564230310500192

Wu, J. H., \& Wang, S. C. (2005). What Drives Mobile Commerce?: An Empirical Evaluation of the Revised Technology Acceptance Model. Information \& Management, 42, 719-729. https://doi.org/10.1016/j.im.2004.07.001

Yousafzai, S. Y., Pallister, J. G., \& Foxall, G. R. (2003). A Proposed Model of E-Trust for Electronic Banking. Technovation, 23, 847-860. https://doi.org/10.1016/S0166-4972(03)00130-5 